\title{
Influence of photodegradation on the removal of color and phenolic compounds from palm oil mill effluent by Arthrospira platensis
}

\author{
M. M. Azimatun Nur ${ }^{1,2}$ D - G. M. Garcia ${ }^{1}$ - P. Boelen ${ }^{1}$ • Anita G. J. Buma ${ }^{1}$
}

Received: 21 March 2020 / Revised and accepted: 22 November 2020 / Published online: 7 December 2020

(C) The Author(s) 2020

\begin{abstract}
Palm oil mill effluent (POME) released from conventional treatment systems poses severe environmental problems due to its dark color, its high chemical oxygen demand (COD), and high content of phenolic compounds. However, the possible biodegradation of phenolic compounds and color by microalgae was not well explored. This research aimed to reveal optimal conditions for pollutant removal through biodegradation by the cyanobacterium Arthrospira platensis. This species was grown under a range of POME fractions and environmental conditions (irradiance, salinity, nutrients) during which growth, final biomass, color, COD, and phenolic compound levels were followed. POME fractions influenced A. platensis growth rate, final biomass, COD, and color removal. The optimization of phenolic compound removal by using central composite design (CCD) response surface methodology (RSM) showed that low light and high initial phenolic compounds promoted the activity of $A$. platensis to degrade phenolic compounds. The combination of high initial phenolic compounds and high light intensity increased the growth rate up to 0.45 days $^{-1}$ and final biomass up to $400 \mathrm{mg} \mathrm{L}^{-1}$, while total phenolic compounds were almost completely (94\%) removed. Finally, this study showed that phenolic compounds and color degradation from POME were dominated by the activity of photodegradation at high irradiance, while the activity of $A$. platensis dominated at low light intensity.
\end{abstract}

Keywords Biodegradation · POME · Arthrospira platensis $\cdot$ Phenolic compounds $\cdot$ Color

\section{Introduction}

Indonesia is the largest palm oil producer in the world. About $600-870 \mathrm{~kg}$ of palm oil mill effluent is generated when processing a tonne of fresh palm fruits. Direct discharge of untreated POME into aquatic environments may cause problems. When POME is released from the palm oil mills, its characteristics are the following: temperature ranges between 70 and $80{ }^{\circ} \mathrm{C}, \mathrm{pH}$ is low (between 4 and 5 ), it is highly colloidal, it has high chemical and biological oxygen demand, and a high concentration of phenolic compounds which give it a particular deep reddish to

M. M. Azimatun Nur

m.m.azimatun.nur@rug.nl; lanaazim@upnyk.ac.id

1 Ocean Ecosystems, Energy and Sustainability Research Institute, University of Groningen, Groningen, The Netherlands

2 Chemical Engineering, Faculty of Industrial Engineering, Universitas Pembangunan Nasional "Veteran",

Yogyakarta, Indonesia brown color (Chaijak et al. 2017). Regulatory standards for POME aim to reduce the wastewater discharges taking chemical oxygen demand (COD) and biological oxygen demand (BOD) as key parameters. However, after reaching regulatory standard parameters, the effluent still has a strong smell, high levels of phenolic compounds, and a dark color that could discomfort the local community and the environment (Igwe and Onyegbado 2007; Poh et al. 2010). Physical treatments using membrane systems such as ultrafiltration and nanofiltration are able to remove the color completely (Ahmad et al. 2006; Amat et al. 2015). However, the investment cost for the membrane filtration system could be too high for a medium to small industry. Furthermore, in conventionally treated aerobic POME, the phenolic compounds can reach concentrations between 280 and $680 \mathrm{mg} \mathrm{L}^{-1}$ and are dominated by gallic acid, followed by p-hydroxybenzoic acid, protocatechuic acid, caffeic acid, syringic acid, and vanillic acid (Chantho et al. 2016). Previous research has shown that the maximum toxicity concentrations for phenolic compounds range between 10 and $24 \mathrm{mg} \mathrm{L}^{-1}$ for humans and between 
9 and $25 \mathrm{mg} \mathrm{L}^{-1}$ for fish (Kulkarni and Kaware 2013). Discharging traditionally treated POME into rivers could thus pose a high environmental risk for the surrounding area. Therefore, additional treatments are needed to eliminate the phenols.

In general, physiochemical and biological methods could be applied to remove phenolic compounds from the wastewater (Mohammadi et al. 2015; Pradeep et al. 2015). Nowadays, wastewater treatment using microalgae is preferable compared to yeast and bacteria since the biomass produced has potentially higher economic value (Surkatti and Al-Zuhair 2018; Nur and Buma 2019). Several strains of microalgae have the capability to utilize phenols as energy sources as reviewed recently (Surkatti and Al-Zuhair 2018; Lindner and Pleissner 2019). Several species such as Anabaena variabilis, Chlorella sp., and Scenedesmus obliquus have shown good efficiency in removing phenolic compounds from wastewater by utilizing it as an organic carbon source in the presence of light (Naoki et al. 1979; Klekner and Kosaric 1992; Scragg 2006; Papazi et al. 2019). It has been reported that phenol degradation involves phenol monooxygenase which converts phenol into catechol, followed by further metabolization processes (Semple and Cain 1996). Lee et al. (2015) found that Arthrospira maxima could remove $400 \mathrm{mg} \mathrm{L}^{-1}$ phenol through biodegradation rather than bioadsorption processes. Several factors such as the type and concentration of the phenolic compounds could influence the rate and efficiency of the removal (Surkatti and Al-Zuhair 2018; Priyadharshini and Bakthavatsalam 2016; Hirooka et al. 2003). Yet, earlier results did not consider phenol removal by photodegradation, although it had been shown that light could contribute to phenolic compound degradation (Lika and Papadakis 2009). In contrast, earlier research found that photodegradation activity also contributed to the antibiotic tetracycline in a domestic wastewater treatment system, using microalgae in the light (Norvill et al. 2017).

Previous research has demonstrated the removal of COD and color by Chlorella sorokiniana by varying POME fractions (Haruna et al. 2018). However, these results did not include the potential role of photodegradation. The presence of photodegradation and microalgae has been found to be important for the degradation of phenolic compounds (Norvill et al. 2017). Nevertheless, the growth of microalgae could also be affected by the light intensity. The relationship between photodegradation and microalgal activity was not well explored so far. Therefore, in the present study, factors affecting phenolic compound and POME color removal were considered by including photodegradation and microalgal activity by varying the initial phenol concentration in POME, irradiance, POME fractions, external nitrogen addition, and salinity. We hypothesized that at high irradiance, phenolic compound and color would be more degraded by photodegradation activity, while at low light irradiance,
A. platensis would relatively be more active degrading phenol and color. Gallic acid was varied and chosen as external phenolic compound since it is the most abundant phenolic compound in POME (Chantho et al. 2016). Arthrospira platensis was chosen since it can be easily cultured in outdoor and large-scale facilities. Furthermore, information on the ability of A. platensis to degrade phenolic compounds is lacking. At the same time, this species synthesizes high value-added compounds such as phycocyanin (Sukumaran et al. 2018; Nur et al. 2019a). The aim of this research was therefore to explore and optimize the utilization of $A$. platensis to remove color and phenolic compounds from POME by varying nutritional and environmental conditions. A range of control experiments (without microalgae) was done, to unravel the contribution of photodegradation to the removal processes under consideration.

\section{Materials and methods}

\section{Wastewater preparation}

Treated POME was obtained from a small factory in Sumatra, Indonesia, as used previously (Nur et al. 2019b). POME was stored at $-20{ }^{\circ} \mathrm{C}$ to avoid degradation over time. Prior to experimental use, POME was thawed and filtered using GF/C glass fiber filter (Whatman) to remove suspended solids followed by autoclaving $\left(121^{\circ} \mathrm{C}, 15 \mathrm{~min}\right)$. Based on an earlier study, the pretreatment process (filtration and autoclave) reduced $22 \%$ and $20 \%$ of color and COD, respectively, compared to raw POME (Nur et al., 2019). Filtered and autoclaved POME contained $1425 \mathrm{mg} \mathrm{L}^{-1} \mathrm{COD}, 56 \mathrm{mg} \mathrm{L}^{-1}$ total dissolved nitrogen, $6.93 \mathrm{mg} \mathrm{L}^{-1}$ dissolved $\mathrm{PO}_{4}{ }^{3-} \mathrm{P}, 240 \mathrm{mg} \mathrm{L}^{-1}$ total phenolic compounds, and 3600 ptco color as estimated by spectrophotometry using appropriate assay kits LCK 318, LCK349, LCK138 (Hach Lange) (Nur et al. 2019b), and Folin-Ciocalteu reagent (Sigma-Aldrich, Netherlands).

\section{Experimental setup}

Arthrospira platensis (SAG 21.99) was from the Culture Collection of Algae of the University of Göttingen (SAG, Germany). The culture was grown and maintained in Zarrouk medium (Zarrouk 1966), at a temperature of $27{ }^{\circ} \mathrm{C}$ and an irradiance of $150 \mu \mathrm{mol}$ photons $\mathrm{m}^{-2} \mathrm{~s}^{-1}$ in a $16: 8 \mathrm{~h}$ light/dark cycle. Three step-wise experiments were executed: the first experiment was aimed to study the effect of POME fraction (in ultrapure water, Milli-Q) on A. platensis growth rate, final biomass, POME color, phenolic compounds, and chemical oxygen demand (COD) removal, without adding external nutrients; the second experiment was done to study the most influencing factor (POME fraction, salinity, irradiance level, and nitrate concentration) as well as their possible 
interactive effects on biomass productivity and total POME color removal by using a factorial design; the third experiment was aimed to examine the interactive effect of irradiance level and initial phenol concentration on growth, final biomass, and phenol removal by A. platensis using central composite design (CCD) response surface methodology (RSM). The cultures were acclimated to the experimental conditions for at least 1 week prior to experimentation.

\section{Effect of POME}

Arthrospira platensis was cultured in duplicate in $100 \mathrm{~mL}$ sterilized Erlenmeyer flasks with $75 \mathrm{~mL}$ working volume. The experimental temperature was set at $27{ }^{\circ} \mathrm{C}$ by placing the flasks in a U-shaped water bath, and cultures were illuminated by a steady light source (Osram Biolux L 36W/965) which was placed in an $\mathrm{U}$ design, in a 16:8 h light/dark cycle as described previously (Nur et al. 2019b).

Five percent (v/v) of culture inoculum, equal to $50 \mathrm{mg} \mathrm{L}^{-1}$ dry weight, was added to five different dilutions of POME in ultrapure water $(10-100 \% \mathrm{v} / \mathrm{v})$, in triplicate. Since natural $100 \%$ POME has 4 PSU salinity, the final salinity for each POME dilution below $100 \%$ was set to 4 PSU by adding $\mathrm{NaCl}$. Furthermore, the initial $\mathrm{pH}$ was set to $9.0 \pm 0.2$ by using $2 \mathrm{~N} \mathrm{HCl}$ or $2 \mathrm{~N} \mathrm{NaOH}$ since A. platensis grows well at high $\mathrm{pH}$. Initial light intensity was set to a saturating level of $200 \mu \mathrm{mol}$ photons $\mathrm{m}^{-2} \mathrm{~s}^{-1}$ for each POME condition, as measured in the center of the $100 \mathrm{~mL}$ sterilized Erlenmeyer culture flasks (75 mL working volume), using a spherical light sensor (Biospherical Instrument QSL2101, USA). The light penetrating into the flask was adjusted by using 1-4 layers of black neutral density screen since the turbidity of POME was different for each fraction. Every day, the optical density of the cells was measured at $750 \mathrm{~nm}$ to determine the growth rate. At the beginning of the incubations, the control (without A. platensis) was analyzed to determine the initial phenol, color, and COD concentration (see analysis section below). At the end of the incubation ( 6 days), final biomass in the culture was determined by centrifugation followed by spectrophotometric detection (see below), whereas COD concentration, color, and phenolic compounds were determined in the supernatant (see analysis section below). To follow photodegradation of POME over time, triplicate control experiments were done by incubating 10-100\% POME without adding A. platensis in the same experimental setup.

\section{Effects of nutritional and environmental conditions}

Arthrospira platensis was cultured in $75 \mathrm{~mL}$ working volume in $100 \mathrm{~mL}$ sterilized Erlenmeyer flasks in a water bath as described above. Five percent (v/v) of A. platensis culture was used as inoculum to the medium as described above. Full factorial design with four variables (POME, salinity, irradiance, nitrate) was performed to reveal the influencing factors and the possible interaction between these factors with respect to POME color removal by A. platensis (Table 1). The experiments were carried out at $27^{\circ} \mathrm{C}$, and the initial $\mathrm{pH}$ was adjusted to $9.0 \pm 0.2$ by using $2 \mathrm{~N} \mathrm{HCl}$ or $2 \mathrm{~N} \mathrm{NaOH}$. Salinity was adjusted using ultrapure water (Milli-Q), $\mathrm{NaCl}$, or natural filter sterilized sea water. At the beginning of the experiment, the control (without $A$. platensis inoculum) was analyzed to determine the initial color. At end of the exponential growth phase (7-10 days), the cultures were centrifuged, and the supernatant was kept to determine color The biomass measurement was done at the beginning and the end of cultivation by using spectrophotometry An additional control experiment was done by incubating POME without adding A. platensis in order to follow photodegradation of POME over time within the same experimental setup. Two replicates were done for the experiment.

\section{Effect of light and initial phenolic compounds}

To understand the interaction between light intensity and phenol addition on growth, final biomass, and phenol removal, different light intensities and concentrations of external gallic acid were applied following the CCD RSM approach. The addition of gallic acid was chosen because this phenolic substance dominates in POME (Chantho et al. 2016), while light intensity was chosen since it was the most influencing factor based on previous experiments ("Effects of nutritional and environmental conditions" section). A fixed POME fraction of $50 \%$ was used in this experimental series since, based on experiment 1 , the final biomass was not significantly lower than $100 \%$ POME. Based on a preliminary experiment, color and phenolic compounds showed a strong correlation $\left(R^{2}=\right.$ 0.95) (Supplementary Material 1). Therefore, different initial phenolic concentrations in POME combined with different light intensities were applied to understand the interaction of these factors. A total of 13 experimental runs were performed (Table 3). The ranges used for these runs were 8.6$290 \mathrm{mg} \mathrm{L}^{-1}$ for gallic acid $\left(x_{1}\right)$ and $80-220 \mu \mathrm{mol}$ photons $\mathrm{m}^{-2} \mathrm{~s}^{-1}$ for initial light intensity $\left(x_{2}\right)$. The empirical form of the second-order polynomial model (Eq. 1) can be described as:

$y=\beta_{0}+\sum \beta_{i} x_{i}+\sum \beta_{i i} x_{i}^{2}+\sum \beta_{i j} x_{i}, x_{j}$

where $y$ is the predicted value; $\beta_{0}, \beta_{i}, \beta_{i i}$, and $\beta_{i j}$ are a constant, linear, quadratic, and the interaction coefficient, respectively; and $x_{i}$, and $x_{j}$ are independent variables of the model.

Cultivation was carried out in the same setup as the first experimental series. Fifty percent of POME (diluted with ultrapure Milli-Q) was mixed with gallic acid, stirred for $4 \mathrm{~h}$ at $1500 \mathrm{rpm}$ at room temperature on a magnetic stirrer (Stuart SD162, England). The initial $\mathrm{pH}$ was adjusted to 
Table 1 Factorial design experiment

\begin{tabular}{lllll}
\hline Run & $\begin{array}{l}\text { POME } \\
(\%)\end{array}$ & $\begin{array}{l}\text { Salinity } \\
(\text { PSU })\end{array}$ & $\begin{array}{l}\text { Light intensity } \\
(\mu \mathrm{mol} \text { photons } \\
\left.\mathrm{m}^{-2} \mathrm{~s}^{-1}\right)\end{array}$ & $\begin{array}{l}\text { Nitrate } \\
\left(\mathrm{mg} \mathrm{L}^{-1}\right)\end{array}$ \\
\hline 1 & 50 & 15 & 50 & 0 \\
2 & 50 & 15 & 50 & 100 \\
3 & 50 & 30 & 50 & 0 \\
4 & 50 & 30 & 50 & 100 \\
5 & 100 & 15 & 50 & 0 \\
6 & 100 & 15 & 50 & 100 \\
7 & 100 & 30 & 50 & 0 \\
8 & 100 & 30 & 50 & 100 \\
9 & 50 & 15 & 200 & 0 \\
10 & 50 & 15 & 200 & 100 \\
11 & 50 & 30 & 200 & 0 \\
12 & 50 & 30 & 200 & 100 \\
13 & 100 & 15 & 200 & 0 \\
14 & 100 & 15 & 200 & 100 \\
15 & 100 & 30 & 200 & 0 \\
16 & 100 & 30 & 200 & 100 \\
\hline
\end{tabular}

$9.0 \pm 0.2$ by using $2 \mathrm{~N} \mathrm{HCl}$ or $2 \mathrm{~N} \mathrm{NaOH}$. Salinity was adjusted to $20 \mathrm{PSU}$ as optimum level by using $\mathrm{NaCl}$ based on previous results (Nur et al. 2019a). External urea ( $800 \mathrm{mg} \mathrm{L}^{-1}$ ) was added to the medium to avoid nitrogen limitation based on previous experiments (Nur et al. 2019a). Every day, the optical density of the culture was measured at $750 \mathrm{~nm}$ to determine the growth rate. At the end of the exponential phase (5 days), the cultures were harvested, and the filtrate was stored to determine phenol removal efficiency. Additional measurements were done to determine the correlation of initial total phenols and initial total color in POME (Supplementary 1). Two additional control experiments were executed: in the first control experiment, 50\% POME was incubated without adding A. platensis (Table 3), in order to follow photodegradation of POME over time under the experimental conditions applied (initial and final sampling only). A second control experiment was done to understand the evolution of color degradation over time for a range of initial phenolic compounds, by performing daily sampling (Supplementary 2). Two replicates were done for the experiment.

\section{Analytical methods}

\section{Growth rate and biomass measurement}

Every day, $3 \mathrm{~mL}$ of sample was taken and centrifuged at $10,000 \mathrm{rpm}$ for $15 \mathrm{~min}$, after which the pellet was resuspended in $3 \mathrm{~mL}$ of ultrapure water (salinity $4 \mathrm{PSU}$ ). This process was repeated twice to avoid color interferences between POME and A. platensis absorption. Growth rate was determined by plotting the relationship between time (days) versus cell absorbance of the natural logarithm of $\mathrm{OD}_{750 \mathrm{~nm}}$. The specified wavelength $(750 \mathrm{~nm})$ was chosen to avoid the interference of $A$. platensis pigments (Griffiths et al. 2011). Growth rate was determined by the slope of the linear regression analysis.

Dry biomass was measured indirectly based on optical density as described previously (Nur et al. 2019a). Since POME may strongly interfere with the A. platensis absorption measurements, samples $(3 \mathrm{~mL})$ were taken and centrifuged at 10,000 rpm for $15 \mathrm{~min}$ to separate the algal biomass from the POME medium. The pellet was washed twice using $0.75 \% \mathrm{NaCl}$ and resuspended in $3 \mathrm{~mL} 4 \mathrm{PSU}$.

Biomass productivity was calculated as described previously (Nur et al. 2019a) following Eq. 2:

$P_{x}=\frac{X_{t}-X_{0}}{t}$

where $P_{x}$ is biomass productivity $\mathrm{mg} \mathrm{L}^{-1}$ day $^{-1}, X_{t}$ is final biomass $\left(\mathrm{mg} \mathrm{L}^{-1}\right), X_{0}$ is initial biomass $\left(\mathrm{mg} \mathrm{L}^{-1}\right)$, and $t$ is total duration of cultivation (day).

\section{Determination of COD}

For COD analysis, samples $(3 \mathrm{~mL})$ were taken and centrifuged at $10,000 \mathrm{rpm}$ for $15 \mathrm{~min}$ to remove A. platensis cells. Two milliliter of the sample (diluted with ultrapure water if necessary) was carefully pipetted to a tube containing reagent LCK314 (Hach, Netherland). This dilution was also used to lower salinity due to the interference of salt during the COD analysis. The tube was gently inverted and then hydrolyzed to a temperature block (Hach LT 200) at $148{ }^{\circ} \mathrm{C}$ for $120 \mathrm{~min}$. After cooling to room temperature, the COD value in the tube was read based on spectrophotometry (Hach, DR3900).

COD removal efficiency was calculated using Eq. 3:

$\operatorname{TCOD}(\%)=\frac{\mathrm{COD}_{0}-\mathrm{COD}_{\mathrm{t}}}{\mathrm{COD}_{0}} \times 100$

where TCOD is total COD removal (\%), $C O D_{0}$ is $\mathrm{COD}$ of the sample at day 0 of cultivation $\left(\mathrm{mg} \mathrm{L}^{-1}\right)$, and $C O D_{t}$ is COD of the sample at the end of cultivation $\left(\mathrm{mg} \mathrm{L}^{-1}\right)$. The calculation of COD removal by A. platensis $\left(\mathrm{COD}_{\mathrm{s}}\right)$ and the control $\left(\mathrm{COD}_{\mathrm{p}}\right)$ were also derived from Eq. 3.

COD removal by A. platensis was corrected by subtracting total COD removal (TCOD) with removal of the COD from control as stated in Eq. 4:

$\mathrm{COD}_{\mathrm{s}}=\mathrm{TCOD}-\mathrm{COD}_{\mathrm{p}}$

where $C O D_{s}$ is COD removal efficiency as a result of activity 
from A. platensis $(\%)$ and $C O D_{p}$ is COD removal efficiency from the control expressing photodegradation activity (\%).

COD removal in absolute value was calculated from Eq. 5:

$$
\mathrm{ACOD}=\mathrm{COD}_{0}-\mathrm{COD}_{\mathrm{t}}
$$

where ACOD is absolute value of COD removed by total activity ( $\left.\mathrm{mg} \mathrm{L}^{-1}\right), \mathrm{COD}_{0}$ is COD at the first day of cultivation ( $\left.\mathrm{mg} \mathrm{L}^{-1}\right)$, and $\mathrm{COD}_{\mathrm{t}}$ is COD at the end of cultivation $\left(\mathrm{mg} \mathrm{L}^{-1}\right)$. Equation 5 was also applied for control as expressed of photodegradation activity and A. platensis activity.

Absolute value of COD removed by A. platensis was corrected by subtracting the absolute total value of COD from control expressing photodegradation following Eq. 6:

$$
\mathrm{ACODs}=\mathrm{ACOD}-\mathrm{ACODp}
$$

where ACODs is the concentration of COD removed by A. platensis activity $\left(\mathrm{mg} \mathrm{L}^{-1}\right), A C O D$ is the concentration COD removed by total activity $\left(\mathrm{mg} \mathrm{L}^{-1}\right)$, and $A C O D p$ is the concentration of COD from control expressing photodegradation activity $\left(\mathrm{mg} \mathrm{L}^{-1}\right)$.

\section{Determination of color removal}

Color measurements were done following Hach (2014) which is suitable for water, wastewater, and seawater samples. Samples $(2 \mathrm{~mL}$ ) were taken and centrifuged at 10,000 rpm for $15 \mathrm{~min}$ to remove A. platensis cells. The supernatant was then diluted in a ratio $1: 3$ by using ultrapure water and measured using a spectrophotometer (Hach Lange DR 3900) at $455 \mathrm{~nm}$. A platinum cobalt standard solution (PtCo) was used to prepare a standard curve of measurements at $455 \mathrm{~nm}$ (spectrophotometer, program 120). Measurements were recorded in PtCon units.

Color removal efficiency was calculated using (Eq. 7):

$\mathrm{TC}=\frac{\mathrm{C}_{0}-\mathrm{C}_{\mathrm{t}}}{\mathrm{C}_{0}} \times 100$

where $T C$ is total color removal (\%), $C_{0}$ is the color of the sample at day 0 of cultivation, and $C_{t}$ is the tcolor of the sample at the end of cultivation. The calculation of color removal by A. platensis $\left(\mathrm{TC}_{\mathrm{s}}\right)$ and the control, representing photodegradation only $\left(\mathrm{TC}_{\mathrm{p}}\right)$, was also applied from Eq. 7.

Color removal by A. platensis was corrected by subtracting total removal with removal of the color from photodegradation activity following Eq. 8:

$\mathrm{TC}_{\mathrm{s}}=\mathrm{TC}-\mathrm{TC}_{\mathrm{p}}$

where $T C_{s}$ is the color removal efficiency as a result of activity from A. platensis (\%) and $T C_{p}$ is the color removal efficiency from the control as a result of photodegradation activity (\%).

Color removal in absolute values was calculated from Eq. 9:
$\mathrm{ATC}=\mathrm{TC} 0-\mathrm{TCt}$

where $A T C$ is the absolute value of color removed by total activity (ptco), $T C_{0}$ is the color at the first day of cultivation (ptco), and $T C_{t}$ is the color at the end of cultivation $\left(\mathrm{mg} \mathrm{L}^{-1}\right)$. Equation 9 was also applied for control expressing photodegradation activity and $A$. platensis activity.

The absolute value of color removed by A. platensis was corrected by subtracting the absolute total value of color from control expressing photodegradation, following Eq. 10:

ATCs $=$ ATC-ATCp

where ATCs is the concentration of color removed by A. platensis activity (ptco), ATC is the concentration color removed by total activity (ptco), and ATCP is the concentration of color removed from control expressing photodegradation activity (ptco).

\section{Determination of phenolic compounds}

Total phenolic compounds were determined by applying minor modifications of the Folin-Ciocalteu method as described previously (Ergül et al. 2011; Chantho et al. 2016). First, samples were centrifuged at $10,000 \mathrm{rpm}$ for $15 \mathrm{~min}$ to eliminate A. platensis. Then, $200 \mu \mathrm{L}$ of the sample (diluted with ultrapure water if necessary) was placed in a $15-\mathrm{mL}$ dark conical tube and mixed with $1 \mathrm{~mL}$ Folin-Ciocalteu phenol reagent (Sigma-Aldrich, Netherlands) (4-fold dilution with ultrapure water). After $5 \mathrm{~min}, 1 \mathrm{~mL}$ of a saturated sodium carbonate solution $\left(200 \mathrm{~g} \mathrm{~L}^{-1}\right)$ was added, vortexed at $2500 \mathrm{rpm}$ for $10 \mathrm{~s}$, and left for $30 \mathrm{~min}$ at room temperature. The absorbance was measured spectrophotometrically (Hach, 5200, Netherland) at $725 \mathrm{~nm}$. A calibration curve of gallic acid was used as a standard, with 5 set points in the range $0-850 \mathrm{mg} \mathrm{L}^{-1}$.

Phenol removal efficiency (TP) was calculated using Eq. 11:

$T P=\frac{P_{0}-P_{\mathrm{t}}}{P_{0}} \times 100$

where TP is total phenol removal (\%), $P_{0}$ is phenol of the sample at day 0 of cultivation $\left(\mathrm{mg} \mathrm{L}^{-1}\right)$, and $P_{t}$ is the concentration of phenol in the sample at the end of cultivation (mg L $\left.{ }^{-1}\right)$.

Phenol removal by A. platensis was corrected by subtracting total phenol removal with phenol removal from the control expressing photodegradation activity as stated in Eq. 12:

$\mathrm{TP}_{\mathrm{s}}=\mathrm{TP}-\mathrm{TP}_{\mathrm{p}}$ 
where $T P_{s}$ is phenol removal efficiency as a result of activity from A. platensis (\%) and $T P_{P}$ is phenol removal efficiency from the control as a result of photodegradation (\%).

The absolute value of total phenolic compounds removed was calculated by Eq. 13:

$$
\mathrm{AbTP}=\mathrm{TP} 0-\mathrm{TPt}
$$

where AbTP is the absolute value of phenolic compounds removed by total activity $\left(\mathrm{mg} \mathrm{L}^{-1}\right), T P_{0}$ is total phenolic compounds at the first day of cultivation $\left(\mathrm{mg} \mathrm{L}^{-1}\right)$, and $T P_{t}$ is total phenolic compounds at the end of cultivation $\left(\mathrm{mg} \mathrm{L}^{-1}\right)$. Equation 9 was also applied for photodegradation activity and $A$. platensis activity.

Concentration of phenol removed by A. platensis was corrected by subtracting the absolute total value of phenolic compounds by the absolute concentration of phenol removed from the control expressing photodegradation activity following Eq. 14:

$\mathrm{ATPs}=\mathrm{AbTP}-\mathrm{ATPp}$

where ATPS is the absolute concentration of phenolic compounds removed by A. platensis activity $\left(\mathrm{mg} \mathrm{L}^{-1}\right), A b T P$ is the concentration of phenolic compounds removed by total activity ( $\mathrm{m} \mathrm{L}^{-1}$ ), and ATPp is the concentration of phenolic compounds removed from the control expressing photodegradation activity $\left(\mathrm{mg} \mathrm{L}^{-1}\right)$.

\section{Data analysis}

Experimental design and statistical analyses were done using ANOVA Factorial Design and Response Surface Methodology, run in Minitab 18. ANOVA analysis was done with $\alpha=0.05$ for attribution of sources of variation. Optimization experiments were generated as per CCD model. Pareto charts and contour plots were used to understand the most influencing factors and the correlations between parameters.

\section{Results}

\section{Effect of POME fraction}

Arthrospira platensis was grew well on all POME fractions, including 100\% POME. Between 10 and 100\% POME final biomass showed an almost 1.5-fold significant increase, whereas POME fractions above $30 \%$ POME showed no significant differences $(P>0.05)$ (Fig. 1). The lowest final biomass was found on $10 \%$ POME $\left(135 \mathrm{mg} \mathrm{L}^{-1}\right)(P<0.05)$, whereas at $100 \%$ POME, a final biomass of $190 \mathrm{mg} \mathrm{L}^{-1}$ was recorded. For growth rate, POME fractions above $30 \%$ showed significantly increased growth rates compared with the lower fractions $(P<0.05)$. No significant differences in growth rate were found between 50 and $100 \%$ POME $(P>0.05)$. The final biomass concentration was increased 2.5 to 3.8 -fold for 10 to $100 \%$ POME, respectively, compared to the initial biomass concentration at day zero.

Increasing the POME fraction from 10 to $20 \%$ significantly enhanced COD removal in absolute value by photodegradation (ACODp), from 28 to $72 \mathrm{mg} \mathrm{L}^{-1}$. Above $30 \%$ POME, no significant increase in ACODp removal was recorded (125 to $245 \mathrm{mg} \mathrm{L}^{-1}$, Table 2). Higher POME fractions also significantly influenced COD removal by A. platensis (ACODs). The highest ACODs was recorded at 100\% POME which removed $317 \mathrm{mg} \mathrm{L}^{-1}(P<0.05)$, and the activity of $A$. platensis, ACODs, was significantly higher compared to photodegradation activity ACODp $(P<0.05)$. The interaction of POME fractions and total activity significantly influenced COD removal in absolute value. By combining photodegradation and A. platensis activity (total activity), the highest absolute value for COD removal was found at 100\% POME $(P<0.05)$ (Table 2$)$.

Absolute phenolic compound removal (ATPp) and color removal (ATCp) were significantly influenced by POME fraction when considering photodegradation activity. Above 50\%, POME fractions significantly influenced the removal of ATPp and ATCp. For A. platensis activity, the removal of phenolic compounds (ATPs) and color (ATCs) were not significantly influenced by POME fractions $(P<0.05)$. At $100 \%$ POME, color was removed up to 2239,365 , and 2605 ptco by photodegradation, A. platensis activity, and total activity, respectively. The highest removal of phenolic compounds and color were found at 100\% POME considering total activity (Table 2). The interaction of total activity and POME fractions significantly influenced the removal of ATC and AbTP $(P<0.05)$. The lowest activity was found for A. platensis activity both for phenolic compounds (ATPs) and color removal (ATCs) $(P<0.05)$.

For COD removal (in percentage value) by photodegradation (CODp), the value was not significantly affected by POME fraction $(P>0.05)$. POME fraction significantly affected COD removal efficiencies by $A$. platensis activity $(\mathrm{CODs})(P<0.05)$ : increasing POME fractions from 10 to $50 \%$ significantly enhanced COD removal efficiencies with almost 3-fold (Fig. 2). For POME fractions above 50\%, CODs removal was not significantly different. When considering total COD removal (TCOD), the lowest removal was found at $10 \%$ POME.

POME fractions influenced the removal efficiency of phenolic compound, both through photodegradation (TPp) and through the activity of A. platensis (TPs). TPp was found to be significantly higher at $100 \%$ POME compared to $50 \%$ POME and lower $(P<0.05)$. However, no significant difference was found between 70 and $100 \% \operatorname{POME}(P>0.05)$. Low phenolic compound removal by $A$. platensis activity (TPs) 
Fig. 1 Final biomass (calculated dry weight in $\mathrm{m} \mathrm{L} \mathrm{L}^{-1}$ ) and growth rate of $A$. platensis cultivated on different POME fractions.

Average values of triplicate cultures are shown. Error bars indicate the SD of the mean. Bar is final biomass; line is growth rate. Values that do not share letters are significantly different $(P<0.05)$

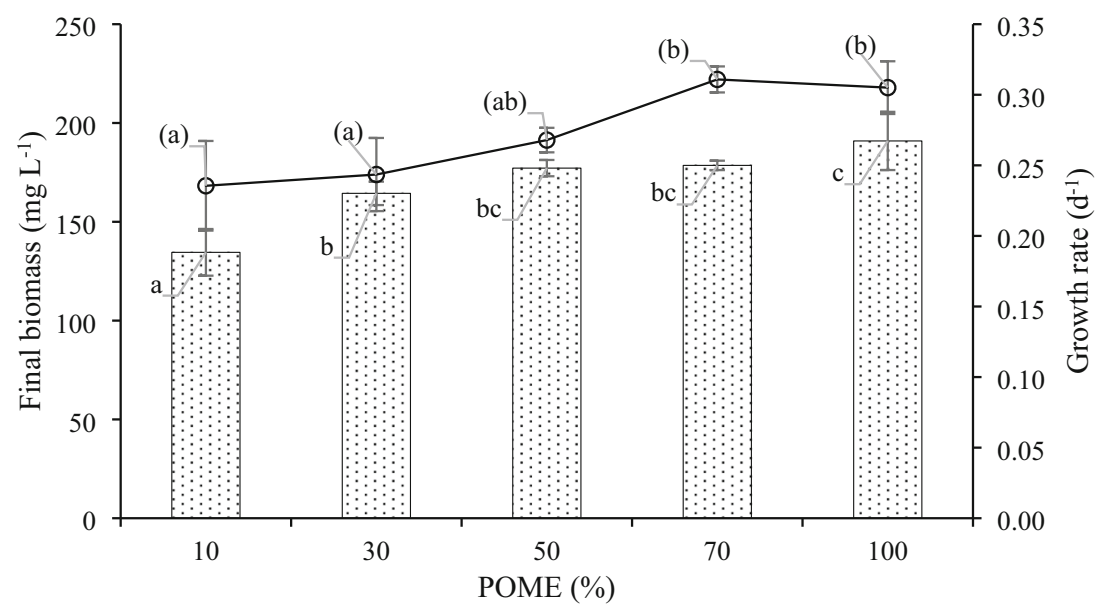

was found for $10 \%$ and $100 \%$ POME, while high TPs removal was found around 30-50\% POME (Fig. 3). For total phenolic compound removal (TP), increasing POME fraction from 10 to $50 \%$ significantly increased removal efficiency $(P<0.05)$. Above 50\% POME fraction, the efficiencies were not significantly different from each other $(P>0.05)$.

Increasing POME fractions from 10 to $100 \%$ also influenced color removal efficiencies by photodegradation (TCp) as well as total activity (TC) $(P<0.05)$ (Fig. 4). However, the POME fraction did not significantly influence color removal based on A. platensis activity (TCs). The highest color removal efficiency was found at $100 \%$ POME both for TCp and TC $(P<0.05)$.

\section{Effect of environmental and nutritional conditions on biomass productivity and total POME color removal}

Environmental and nutritional conditions were studied to understand the interactive factors with respect to color removal and biomass produced by A. platensis. The most influencing factor for biomass productivity was found to be light intensity alone (Fig. 5a). Increasing light intensities, from 50 to $200 \mu \mathrm{mol}$ photons $\mathrm{m}^{-2} \mathrm{~s}^{-1}$, significantly enhanced A. platensis biomass productivity $(P<0.05)$ (Fig. 5a). Increasing salinity, from 15 to 30 PSU, significantly decreased the final biomass $(P<0.05)$ (Fig. 5a). The presence of nitrate at high POME also significantly enhanced biomass
Table 2 COD removal, phenolic removal, and color removal in absolute values at different POME fractions (\%) and activities (photodegradation activity, A. platensis activity, and total activity)

\begin{tabular}{|c|c|c|c|c|c|c|c|}
\hline \multirow{2}{*}{$\begin{array}{l}\text { POME } \\
10\end{array}$} & \multirow{2}{*}{$\begin{array}{l}\text { Activity } \\
\text { Photodegradation }\end{array}$} & \multicolumn{2}{|c|}{$\begin{array}{l}\text { COD removal } \\
\left(\mathrm{mg} \mathrm{L}^{-1}\right)\end{array}$} & \multicolumn{2}{|c|}{ Color removal (ptco) } & \multicolumn{2}{|c|}{$\begin{array}{l}\text { Phenolic compounds } \\
\text { removal }\left(\mathrm{mg} \mathrm{L}^{-1}\right)\end{array}$} \\
\hline & & $28.63^{\mathrm{a}}$ & \pm 1.48 & $105.67^{\mathrm{a}}$ & \pm 20.31 & $11.46^{\mathrm{a}}$ & \pm 3.03 \\
\hline 30 & Photodegradation & $72.33^{\mathrm{b}}$ & \pm 6.81 & $389.67^{\mathrm{b}}$ & \pm 22.59 & $33.65^{\mathrm{b}}$ & \pm 1.17 \\
\hline 50 & Photodegradation & $147.00^{\mathrm{c}}$ & \pm 19.29 & $737.67^{\mathrm{c}}$ & \pm 53.16 & $69.32^{\mathrm{c}}$ & \pm 7.95 \\
\hline 70 & Photodegradation & $217.67^{\mathrm{d}}$ & \pm 6.03 & $1377.33^{\mathrm{d}}$ & \pm 35.57 & $108.21^{\mathrm{d}}$ & \pm 7.20 \\
\hline 100 & Photodegradation & $317.00^{\mathrm{e}}$ & \pm 41.07 & $2239.33^{\mathrm{e}}$ & \pm 54.50 & $171.25^{\mathrm{e}}$ & \pm 1.75 \\
\hline 10 & A. platensis & $17.03^{(a)}$ & \pm 2.70 & $37.33^{\text {(a) }}$ & \pm 9.24 & $0.00^{(\mathrm{a})}$ & \pm 0.00 \\
\hline 30 & A. platensis & $55.67^{(a)}$ & \pm 8.14 & $163.67^{(\mathrm{b})}$ & \pm 8.96 & $10.74^{(\mathrm{a})}$ & \pm 2.23 \\
\hline 50 & A. platensis & $125.00^{(\mathrm{b})}$ & \pm 36.50 & $225.67^{(\mathrm{b})}$ & \pm 54.37 & $21.17^{(\mathrm{a})}$ & \pm 16.22 \\
\hline 70 & A. platensis & $152.33^{(\mathrm{b})}$ & \pm 33.86 & $166.00^{(\mathrm{b})}$ & \pm 28.84 & $12.76^{(a)}$ & \pm 10.48 \\
\hline 100 & A. platensis & $246.33^{(\mathrm{c})}$ & \pm 20.50 & $365.67^{(\mathrm{c})}$ & \pm 56.75 & $4.28^{(\mathrm{a})}$ & \pm 6.29 \\
\hline 10 & Total & $45.67^{\mathrm{A}}$ & \pm 4.04 & $143.00^{\mathrm{A}}$ & \pm 18.52 & $5.48^{\mathrm{A}}$ & \pm 1.09 \\
\hline 30 & Total & $128.00^{\mathrm{A}}$ & \pm 6.93 & $553.33^{\mathrm{B}}$ & \pm 15.28 & $44.39^{\mathrm{B}}$ & \pm 1.09 \\
\hline 50 & Total & $272.00^{\mathrm{B}}$ & \pm 30.20 & $963.33^{\mathrm{C}}$ & \pm 75.06 & $90.49^{\mathrm{C}}$ & \pm 8.27 \\
\hline 70 & Total & $370.00^{\mathrm{C}}$ & \pm 30.00 & $1543.33^{\mathrm{D}}$ & \pm 56.86 & $120.97^{\mathrm{D}}$ & \pm 3.30 \\
\hline 100 & Total & $563.33^{\mathrm{D}}$ & \pm 61.10 & $2605.00^{\mathrm{E}}$ & \pm 10.00 & $175.03^{\mathrm{E}}$ & \pm 5.15 \\
\hline
\end{tabular}

Average values are shown $(n=3)$. Value after \pm symbol indicates standard deviation. Values that do not share the same letters indicate significant difference $(P<0.05)$ 
Fig. 2 Total COD removal (TCOD), COD removal by photodegradation (CODp), and by A. platensis activity (CODs), as a function of POME fraction. Average values of triplicate incubations are shown. Error bars indicate the SD of the mean. TCOD is shown as black bar, CODp is shown as gray bar, and CODs is shown as white bar. Values that do not share letters are significantly different $(P<0.05)$ $\square$ TCOD $\square$ CODp $\square$ CODs

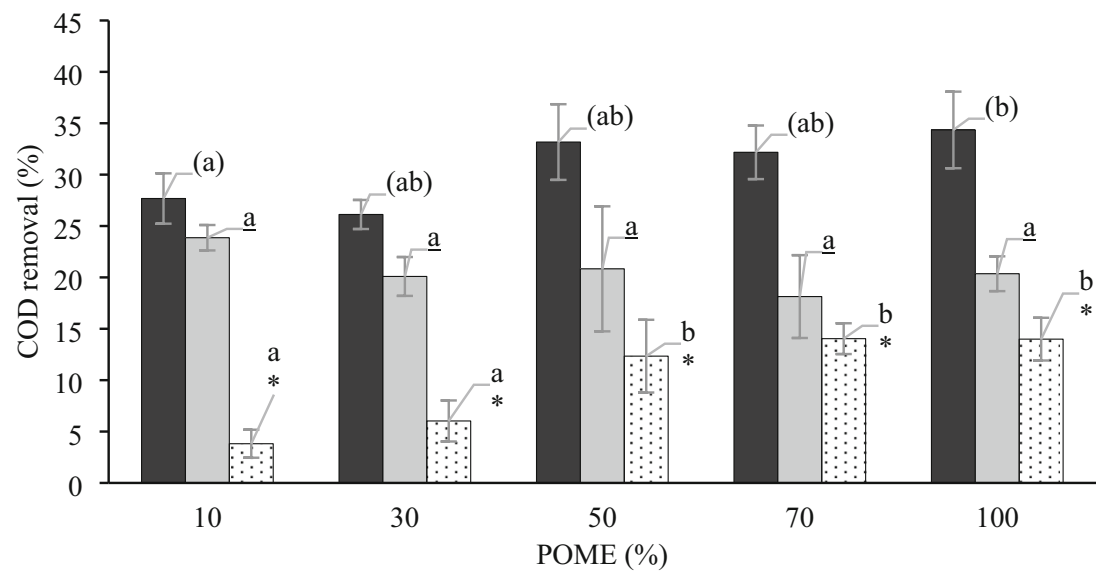

productivity when the irradiance level was high (Fig. 5a). However, based on Pareto chart, the addition of nitrate alone, POME alone, and salinity alone did not enhance biomass productivity $(P>0.05)$.

For total color removal (TC), the most influencing factor was found to be irradiance only (Fig. 5b), while the other factors were not significantly influential. When considering the activity of $A$. platensis alone (TCs), none of the factors significantly influenced the color removal (Fig. 5c). Based on these results, light intensity was optimized to explore phenolic compound removal as the activity of $A$. platensis normalized to photodegradation (third experimental series).

\section{Effect of light intensity and initial phenol concentration on phenol and color removal efficiency}

Since light intensity was found to be the most influencing factor for color removal (second experimental series, Fig. $5 b$ ), the third experimental series was done to reveal the effect of photodegradation on phenolic compound removal during the cultivation of $A$. platensis. We plotted the effect of light intensity and initial phenol concentration on phenol removal using POME only (without A. platensis, TPp). Phenolic compound removal was significantly influenced by light intensity and initial phenol concentration (Fig. 6a). Low initial phenol concentration and increasing light intensity (from 50 to $200 \mu \mathrm{mol}$ photons $\mathrm{m}^{-2} \mathrm{~s}^{-1}$ ) resulted in increasing phenolic compound removal from 30 to $70 \%$. At a higher initial phenol concentration, the phenol removal increased from 60 up to $80 \%$. Both the increasing initial phenol concentration and light intensity resulted in enhanced phenol removal efficiency.

For total phenol removal by A. platensis (TPs) which included the activity of $A$. platensis alone, increasing light intensity decreased phenolic compound removal efficiency (Fig. 6b). At low light (LL) $\left(<100 \mu \mathrm{mol}\right.$ photons $\left.\mathrm{m}^{-2} \mathrm{~s}^{-1}\right)$, phenol degradation reached up to $30-40 \%$ for all initial phenol concentrations. When the light level exceeded $150 \mu$ mol photons $\mathrm{m}^{-2} \mathrm{~s}^{-1}$, TPs was significantly lower, at around $10-15 \%$.

For total phenol removal (TP), the highest phenol removal (>90\%) was recorded when a medium irradiance level (ML) (100-150 $\mu \mathrm{mol}$ photons $\mathrm{m}^{-2} \mathrm{~s}^{-1}$ ) and high initial phenol concentration were employed. The lowest phenol removal $(<$
Fig. 3 Total phenol removal (TP), phenol removal by photodegradation (TPp), and by A. platensis activity (TPs). Average values of triplicate cultures are shown. Error bars indicate the SD of the mean. TP is shown as black bar, TPp is shown as gray bar, and TPs is shown as white bar. Values that do not share letters are significantly different $(P<0.05)$

$$
\square \mathrm{TP} \quad \square \mathrm{TPp} \quad \square \mathrm{TPs}
$$

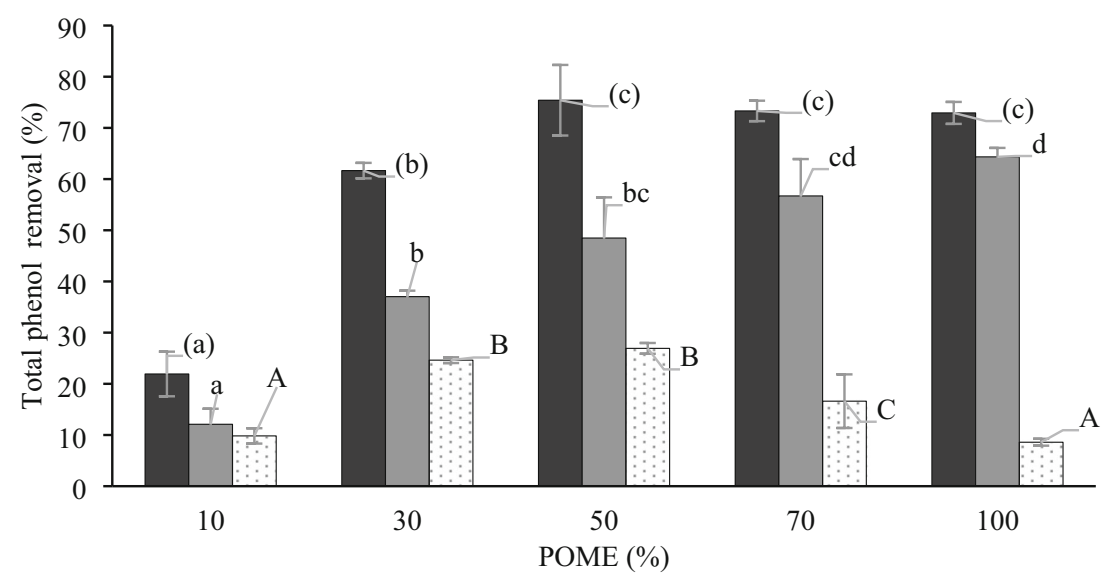


Fig. 4 Total color removal (TC), color removal by photodegradation (TCp), and by A. platensis (TCs) activity. Average values of triplicate cultures are shown. Error bars indicate the SD of the mean. TC is shown as black bar, TCp is shown as gray bar, and TCs is shown as white bar. Values that do not share letters are significantly different $(P<0.05)$
- TC $\square \mathrm{TCp} \quad \square \mathrm{TCs}$

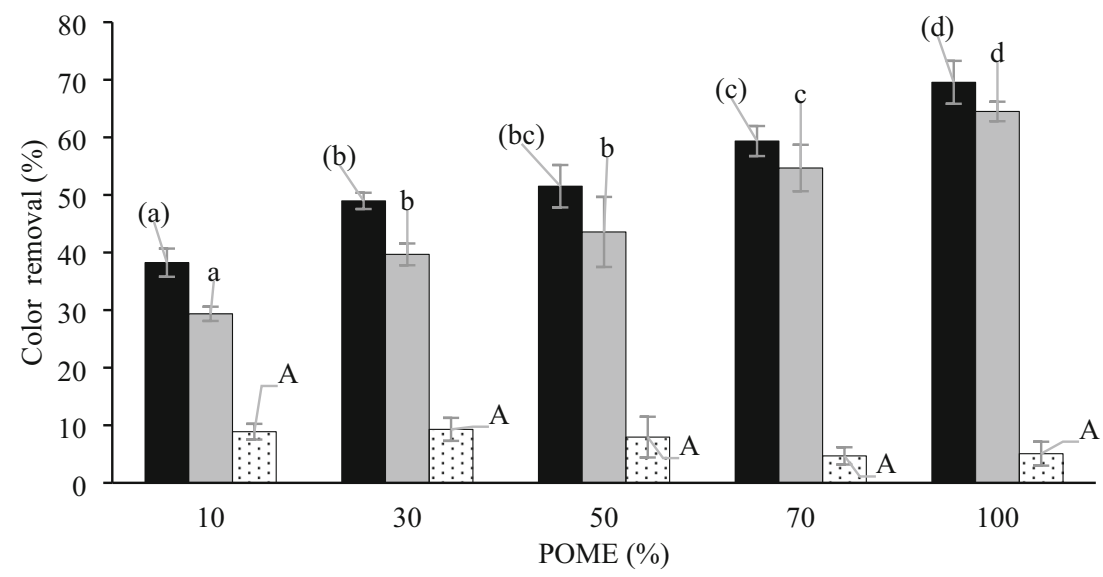

$75 \%$ ) was recorded at low light and low initial phenol concentration (Fig. 6c).

For the absolute concentration of total phenolic compounds removed by $A$. platensis activity (CTPs), increasing light intensity decreased phenolic compound removal, but these differences were not significant $(P=0.052)$. However, when initial total phenolic compounds were increased at lower light intensity, the concentration of phenolic compounds removed by A. platensis was found to be higher (Table 3 ). The interaction of light intensity and initial total phenolic compounds significantly influenced CTPs $(P<0.05)$. Based on RSM calculation, the highest concentration of total phenolic compounds removed by $A$. platensis was found at $80 \mu \mathrm{mol}$ photons $\mathrm{m}^{-2} \mathrm{~s}^{-1}$ and $411 \mathrm{mg} \mathrm{L}^{-1}$ of initial phenolic compounds which resulted in $136 \mathrm{mg} \mathrm{L}^{-1}$ CTPs.

\section{Effect of light intensity and initial phenol concentration on growth rate and final biomass}

The highest final A. platensis biomass (>400 $\mathrm{mg} \mathrm{L}^{-1}$ ) was recorded at high irradiance (HL) (> $150 \mu \mathrm{mol}$ photons $\mathrm{m}^{-2} \mathrm{~s}^{-1}$ ) and high initial phenol concentration. The interaction of light intensity and initial phenol concentration significantly influenced the final biomass. When the light was set to HL, the final biomass was significantly influenced by initial phenol concentration (Fig. 7a). However, at LL, the increase of initial phenol concentration did not significantly influence final biomass production.

The highest growth rate $\left(>0.45\right.$ days $\left.^{-1}\right)$ was also recorded at HL and high initial phenol concentration. At HL, the increase of initial phenol concentration significantly boosted the growth rate, while at LL, the increase of initial phenol concentration decreased the growth rate. Growth rate was significantly influenced by the interaction of light intensity and initial phenol concentration (Fig. 7b).

\section{Discussion}

In the present work, the color of POME was strongly correlated to phenolic compound concentration. The degradation of phenolic compounds was significantly influenced by the activity of photodegradation which also contributed to the degradation of color. It is possible that the presence of hydroxyl radicals $\left(\mathrm{OH}^{-}\right)$, which are generated from irradiated fulvic acid-like substances in POME (Kongnoo et al. 2012), could degrade the phenolic compounds. Faust and Hoigne (1987) found that the combination of fulvic acid and sunlight could enhance the degradation of 2,4,6-trimethylphenol in natural waters, while Jacobs et al. (2012) found that the degradation of phenolic compound occurred through reaction with the hydroxyl radical $\left(\mathrm{OH}^{-}\right)$generated by irradiated fulvic acids. Possibly, at POME fractions above 50\%, photodegradation became more pronounced, due to higher fulvic acid-like concentrations, resulting in higher absolute phenolic compound removal (ATPp). However, at very low POME values, it seems that color could not be degraded by the combined action of fulvic acid and light (see Supplementary 2). Furthermore, the presence of $A$. platensis activity could not significantly enhance the removal. This result is in agreement with a previous study which reported that the color of POME not only consisted of phenolic compounds but also of fulvic acid, humic acid, tannin, and lignin which could not be degraded by simple physical-chemical methods (Kongnoo et al. 2012). Furthermore, previous studies reported that simple phenolic compounds which contained lower hydroxyl group bound to the aromatic ring such as gallic acid were more easily degraded by hydroxyl radicals compared to more complex phenolic compounds such as caffeic acid and protocatechuic, which also contribute to color (Chantho et al. 2016; Sroka and Cisowski 2003).

Compared to photodegradation, the activity of $A$. platensis to remove phenolic compounds (ATPs) and color (ATCs) on 
a)

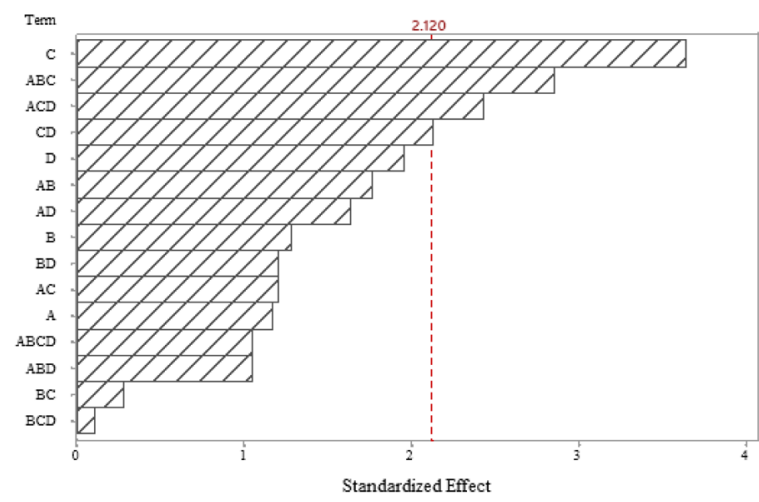

b)

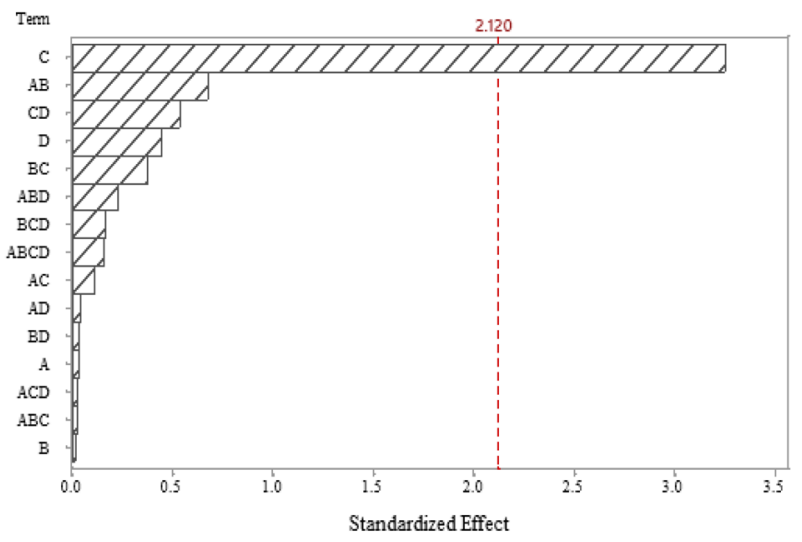

c)

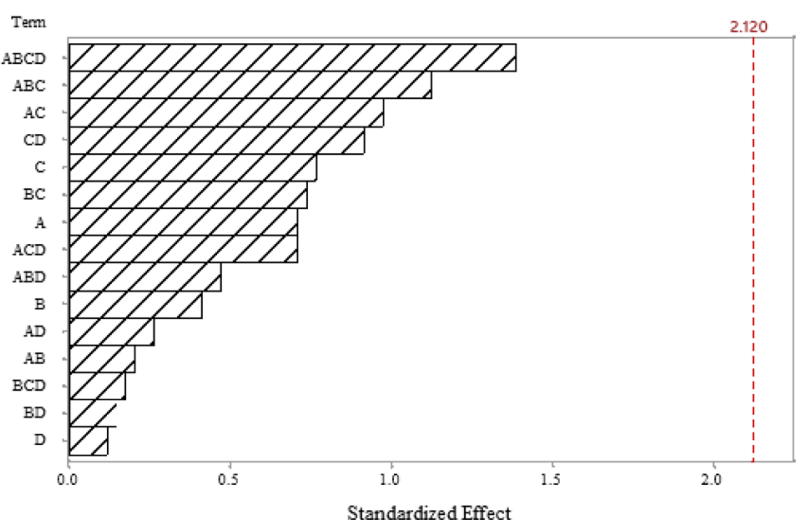

Fig. 5 Pareto chart showing the effects of the parameters on (a) biomass productivity, (b) total color removal (TC), and (c) color removal by A. platensis (TCs). A is POME, B is salinity, C is light intensity, and D is nitrate addition. The vertical line indicates the significance of the effects at $95 \%$ confidence level

POME fractions was lower. In experiment 1 , with high irradiance levels (Table 2), A. platensis only contributed around 10-25\% (Figs. 3 and 4). This indicated that A. platensis activity to remove phenolic compounds on POME was depended on the activity of photodegradation. At high light intensity, hydroxyl radical can be more produced by fulvic acid and resulted higher photodegradation activity. This result was supported by experiment 3 which showed that the activity of A. platensis to remove phenolic compounds in absolute value was lower compared to photodegradation at high irradiance, and vice versa (Table 3 ).

In this study, a combination of fulvic acid present in POME and light intensity also influenced absolute COD by photodegradation (ACODp) (Fig. 2). At 100\% POME, $246.33 \mathrm{mg} \mathrm{L}^{-1}$ of COD was removed by photodegradation. However, at $10 \%$ POME, only $28.63 \mathrm{mg} \mathrm{L}^{-1}$ was removed. In this work, the presence of phenolic compounds seems to contribute to COD. At $100 \%$ POME, the decrease in phenolic compounds was found to be up to $65 \%$, while COD only decreased up to $20 \%$ through photodegradation activity. The decrease of phenolic and color were not consistent with COD removal (Figs. 2, 3, and 4). This indicates that COD in POME consists of complex organic material such as acids, phenols, and tannins. Photodegradation activity was not enough to lower COD content to a very low level, while the presence of A. platensis activity could be promising to lower COD content when their cell concentration is high.

Previous research showed that total organic carbon in POME, which is associated with COD, was degraded in the presence of the hydroxyl radical and metals such as $\mathrm{Fe}^{2+}$ (Gamaralalage et al. 2019). It seems that trace metals contained in POME, such as iron, zinc, and copper, could also contribute to COD degradation after reacting with the hydroxyl radical (Safarzadeh-Amiri et al. 1996; Hurtado et al. 2016; Ding et al. 2016). Increasing the POME fraction might therefore result in higher iron and hydroxyl levels, thereby enhancing ACODp through photodegradation. Furthermore, the value of ACODp was significantly higher compared to COD degradation by A. platensis activity (ACODs). This indicates that the physical processes derived from photodegradation more quickly degraded COD compared to biological process. Previous work reported that digested POME contains approximately $180 \mathrm{mg} \mathrm{L}^{-1}$ of iron (Shavandi et al. 2012).

In the presence of A. platensis, ACODs and total biomass was higher at increasing POME fractions. It is possible that higher POME fractions result in higher organic carbon levels which can be utilized by A. platensis for growth, resulting in higher biomass and higher breakdown of ACOD. This is supported by an earlier study, which demonstrated that organic carbon in treated POME such as acetic acid could be utilized as organic carbon source by $A$. platensis in mixotrophic conditions (Zainal et al. 2012). Poh et al. (2010) reported that digested POME contains acetic acid at concentrations between 1150 and $3500 \mathrm{mg} \mathrm{L}^{-1}$.

With respect to the environmental factors, light intensity significantly enhanced the removal of total color (TC). Previous study found that at higher light intensities, phenol oxidation was more enhanced (Blaková et al. 1998), thus 
Fig. 6 Response surface plot (3D) of (a) total phenolic compound removal by photodegradation (TPp), (b) total phenolic compound removal by A. platensis (TPs), and (c) total phenolic compound removal (TP), as a function of initial light intensity and initial total phenolic compounds

a)

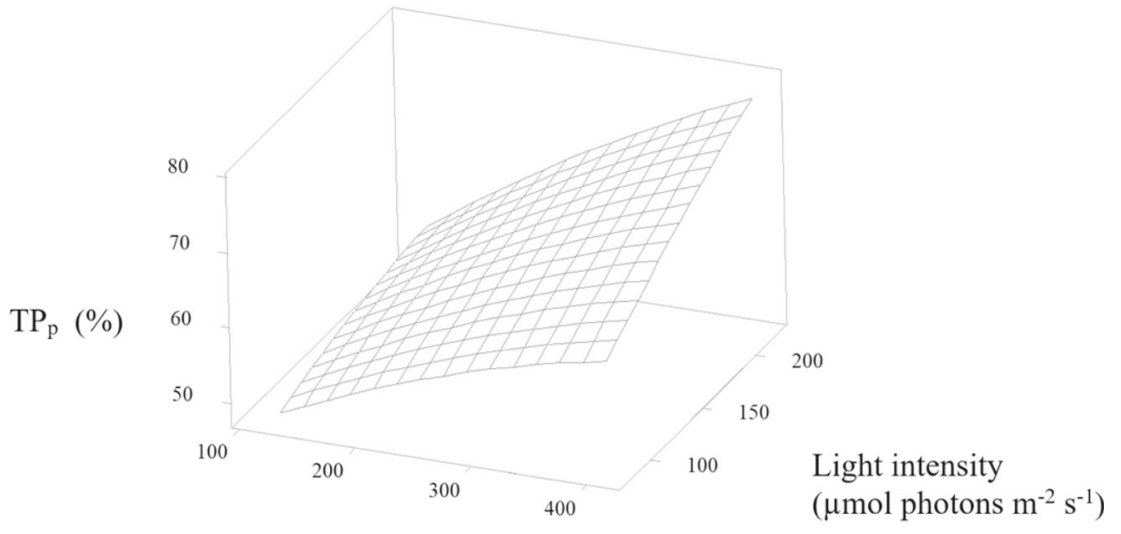

Initial total phenol $\left(\mathrm{mg} \mathrm{L}^{-1}\right)$

b)

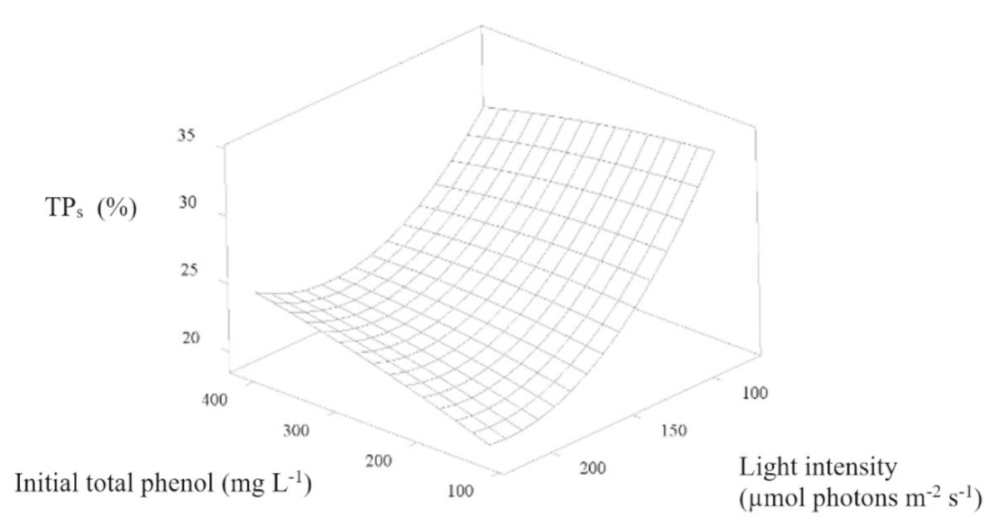

c)

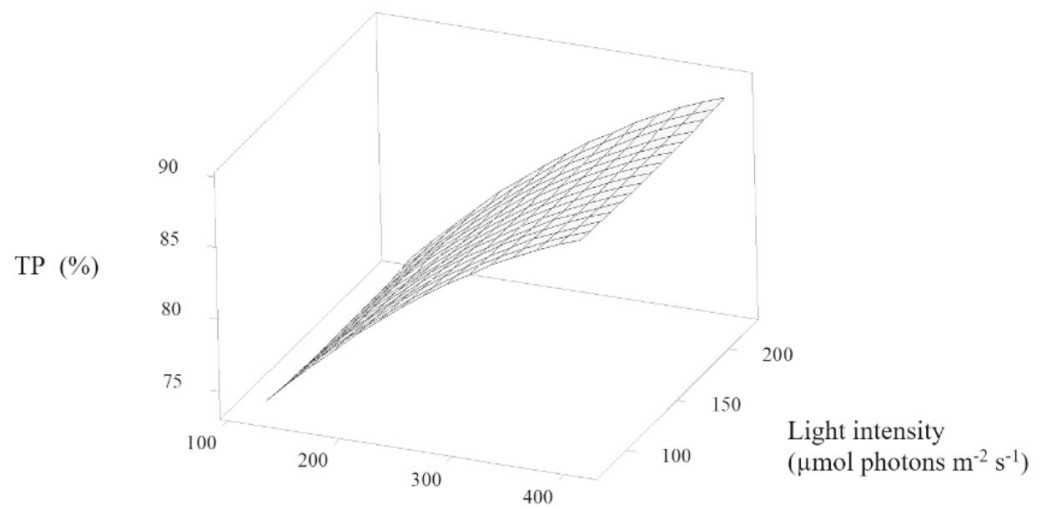

Initial total phenol $\left(\mathrm{mg} \mathrm{L}^{-1}\right)$

resulting higher color removal. While for color removal by A. platensis, the activity was not significantly affected by the selected environmental factors (Fig. 6c), even though the biomass productivity of $A$. platensis was significantly affected by light intensity and the interaction of light intensity and nitrate, the interaction of POME fractions and salinity, and the interaction of POME fractions and nitrate addition (Fig. 5a). It seems that a very high microalgal biomass is required to eliminate all color of POME. Baldev et al. (2013) reported that the removal of a synthetic dye was influenced by the initial inoculum concentration of Coelastrella sp. At the higher initial inoculum concentration, a higher number of the cells were 
Table 3 Experimental design of CCD RSM and the responses of phenolic removal in absolute values

Fig. 7 Response surface plot (3D) of (a) final biomass expressed as dry weight $\left(\mathrm{mg} \mathrm{L}^{-1}\right)$ and (b) growth rate as a function of initial light intensity and initial total phenolic compounds

\begin{tabular}{|c|c|c|c|c|c|c|c|c|}
\hline \multirow{2}{*}{$\begin{array}{l}\text { External } \\
\text { GA } \\
\text { addition } \\
\left(\mathrm{mg} \mathrm{L}^{-1}\right) \\
8.58\end{array}$} & \multirow{2}{*}{$\begin{array}{l}\begin{array}{l}\text { Initial total } \\
\text { phenolic } \\
\left(\mathrm{mg} \mathrm{L}^{-1}\right)\end{array} \\
128.58\end{array}$} & \multirow{2}{*}{$\begin{array}{l}\begin{array}{l}\text { Initial light } \\
\text { intensity }(\mu \mathrm{mol} \\
\text { photons } \\
\left.\mathrm{m}^{-2} \mathrm{~s}^{-1}\right)\end{array} \\
150.00\end{array}$} & \multicolumn{2}{|c|}{$\operatorname{AbTP}\left(\mathrm{mg} \mathrm{L}^{-1}\right)$} & \multicolumn{2}{|c|}{$\operatorname{ATPp}\left(\mathrm{mg} \mathrm{L}^{-1}\right)$} & \multicolumn{2}{|c|}{ ATPs (mg L $\left.{ }^{-1}\right)$} \\
\hline & & & 96.68 & \pm 3.93 & 81.03 & \pm 0.49 & 15.65 & \pm 4.43 \\
\hline 50.00 & 170.00 & 100.00 & 129.36 & \pm 1.97 & 71.99 & \pm 0.49 & 57.38 & \pm 1.48 \\
\hline 50.00 & 170.00 & 200.00 & 138.75 & \pm 2.46 & 117.19 & \pm 0.49 & 21.56 & \pm 2.95 \\
\hline $150.00^{*}$ & $270.00^{*}$ & $150.00^{*}$ & 231.60 & \pm 0.98 & 207.26 & \pm 0.98 & 24.34 & \pm 1.97 \\
\hline 150.00 & 270.00 & 220.71 & 232.30 & \pm 0.00 & 209.00 & \pm 3.44 & 23.30 & \pm 3.44 \\
\hline 150.00 & 270.00 & 79.29 & 235.78 & \pm 5.90 & 182.22 & \pm 36.39 & 53.55 & \pm 30.49 \\
\hline 250.00 & 370.00 & 100.00 & 324.46 & \pm 0.49 & 207.96 & \pm 1.97 & 116.50 & \pm 2.46 \\
\hline 250.00 & 370.00 & 200.00 & 339.06 & \pm 7.38 & 311.59 & \pm 3.93 & 27.47 & \pm 3.44 \\
\hline 291.42 & 411.42 & 150.00 & 374.18 & \pm 11.80 & 338.71 & \pm 6.89 & 35.47 & \pm 4.92 \\
\hline
\end{tabular}

Average values of the response are shown from duplicate experiments $(n=2)$. SD is shown after the \pm symbol. AbTP is the concentration of phenolic compounds removed by total activity ( $\left.\mathrm{mg} \mathrm{L}^{-1}\right)$, ATPp is concentration of phenolic compounds removed by photodegradation activity $\left(\mathrm{mg} \mathrm{L}^{-1}\right)$, and ATPs is concentration of phenolic compounds removed by $A$. platensis activity $\left(\mathrm{mg} \mathrm{L}^{-1}\right)$. * is the middle value in CCD RSM design

a)

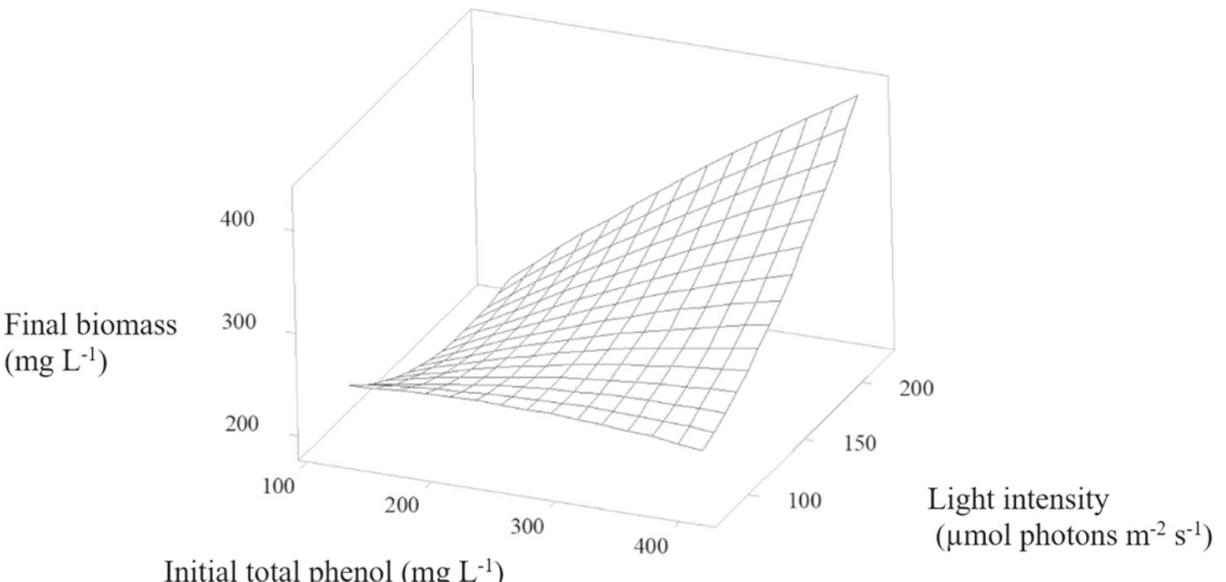

b)

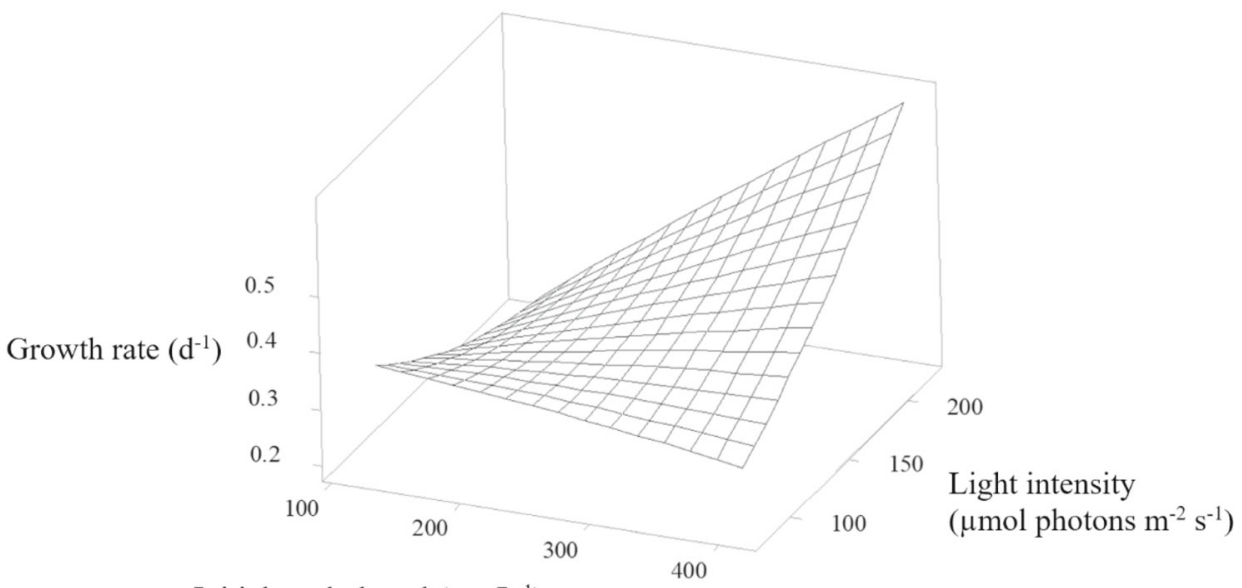

Initial total phenol $\left(\mathrm{mg} \mathrm{L}^{-1}\right)$ 
exposed to the medium, thereby enhancing dye removal. Furthermore, Stephen and Ayalur (2017) found that Chlorella pyrenoidosa at an initial inoculum of around 3$4 \mathrm{~g} \mathrm{~L}^{-1}$ could remove phenol up to $95 \%$ when supplemented with nutrients.

CCD RSM revealed that increasing initial phenolic compounds and light intensity significantly enhanced the phenol removal efficiency by photodegradation. It seems that gallic acid as the external phenolic compound was easily degraded by photodegradation. The higher gallic acid concentrations were applied, and the higher removal efficiency was obtained. On the long run, however, the remaining phenolic compounds are probably more difficult to degrade, and the remaining phenolic compounds could not be removed (see Supplementary 2).

Previous work demonstrated that microalgae could degrade phenolic compounds in several ways: by utilizing it as an organic carbon source or by oxidizing it due to the binding of dissolved oxygen produced by microalgae (Lika and Papadakis 2009). In our study, at low light intensity, photodegradation activity was low. It is possible that the hydroxyl radical produced from fulvic acid in POME was low at low light, thereby causing lower phenolic degradation rates. On the other hand, the degradation of phenolic compounds by A. platensis was high at low light intensity. This might imply that the phenolic compounds were assimilated by A. platensis, which would be in agreement with previous work demonstrating phenolic compound uptake by the cyanobacterium Arthrospira (Spirulina) maxima as organic carbon source (Lee et al. 2015). However, when the irradiance level was high, photodegradation became more pronounced compared with A. platensis activity (Table 3, Fig. 6b), even though A. platensis still contributed to phenolic compound removal at around 10 $20 \%$. This indicated that phenol removal was not directly linked to biomass growth at high light intensity. When photodegradation activity became more active, the presence of phenolic compounds as organic carbon source became limiting for the growth of A. platensis, even though the final biomass concentration was high. A possible explanation for this is that the degradation of phenol at high light intensity resulted in lower molecular weight acids which could be easily utilized by A. platensis (Vlyssides et al. 2011; Golmakani et al. 2012; Gamaralalage et al. 2019).

Nevertheless, the increase in final biomass seems inhibited the photodegradation activity. It was found that increasing irradiance from 150 to $200 \mu \mathrm{mol}$ photons $\mathrm{m}^{-2} \mathrm{~s}^{-1}$ at $400 \mathrm{mg} \mathrm{L}^{-1}$ initial phenolic compound could not promote TPp which is almost stagnant at $80 \%$ (Fig. 6a), while biomass concentration increased from 300 to $400 \mathrm{mg} \mathrm{L}^{-1}$. By combining high light intensity and high initial phenolic compound level, the final biomass and growth rate also increased.

\section{Conclusion}

This study reveals the capability of photodegradation activity to degrade COD, color, and phenolic compounds in POME wastewater in the presence of $A$. platensis. The initial fraction of POME that was present influenced growth rate, final biomass, COD removal absolute value, and absolute color removal by A. platensis. Based on a factorial design approach, it was shown that salinity, nitrogen addition, and initial POME concentration did not influence total color removal. High initial phenolic compound and high light intensity could increase the growth rate up to 0.45 days $^{-1}$ and final biomass up to $400 \mathrm{~g} \mathrm{~L}^{-1}$, while on the other hand, total phenolic compounds were removed almost completely (94\%). Photodegradation activity significantly contributed to color and phenolic compound removal. Phenolic compounds that are present in POME could be removed by A. platensis when cultivated on high POME fractions at low irradiance conditions. High phenolic compound removal can be achieved by combining A. platensis activity and photodegradation, while both activities seem not effective in lowering COD content. Overall, this study shows that phenolic compounds and color degradation from POME are dominated by the activity of photodegradation at high irradiance, while the activity of A. platensis dominates at low light intensity.

Supplementary Information The online version contains supplementary material available at https://doi.org/10.1007/s10811-020-02341-8.

Funding This project was funded by Lembaga Pengelola Dana Pendidikan (LPDP), Kementerian Keuangan, Republik Indonesia (reference no. PRJ-72/LPDP.3/2016).

Open Access This article is licensed under a Creative Commons Attribution 4.0 International License, which permits use, sharing, adaptation, distribution and reproduction in any medium or format, as long as you give appropriate credit to the original author(s) and the source, provide a link to the Creative Commons licence, and indicate if changes were made. The images or other third party material in this article are included in the article's Creative Commons licence, unless indicated otherwise in a credit line to the material. If material is not included in the article's Creative Commons licence and your intended use is not permitted by statutory regulation or exceeds the permitted use, you will need to obtain permission directly from the copyright holder. To view a copy of this licence, visit http://creativecommons.org/licenses/by/4.0/.

\section{References}

Ahmad AL, Chong MF, Bhatia S, Ismail S (2006) Drinking water reclamation from palm oil mill effluent (POME) using membrane technology. Desalination 191:35-44 
Amat NA, Tan YH, Lau WJ, Lai GS, Ong CS, Mokhtar NM, Sani NAA, Ismail AF, Chong KC, Lai SO (2015) Tackling colour issue of anaerobically-treated palm oil mill effluent using membrane technology. J Water Process Eng 8:221-226

Baldev E, MubarakAli D, Ilavarasi A, Pandiaraj D, Ishack KSS, Thajuddin N (2013) Degradation of synthetic dye, Rhodamine B to environmentally non-toxic products using microalgae. Colloids Surfaces B 105:207-214

Blaková A, Csölleová L, Brezova V (1998) Effect of light sources on the phenol degradation using $\mathrm{Pt} / \mathrm{TiO}_{2}$ photocatalysts immobilized on glass fibres. J Photochem Photobiol A 113:251-256

Chaijak P, Lertworapreecha M, Sukkasem C (2017) Decolorization and phenol removal of palm oil mill effluent by termite-associated yeast. Int J Biotechnol Bioeng 11:29-32

Chantho P, Musikavong C, Suttinun O (2016) Removal of phenolic compounds from palm oil mill effluent by thermophilic Bacillus thermoleovorans strain $\mathrm{A} 2$ and their effect on anaerobic digestion. Int Biodeterior Biodegrad 115:293-301

Ding GT, Yaakob Z, Takriff MS, Salihon J, Rahaman MSA (2016) Biomass production and nutrients removal by a newly-isolated microalgal strain Chlamydomonas sp in palm oil mill effluent (POME). Int J Hydrog Energy 41:4888-4895

Ergül FE, Sargın S, Öngen G, Sukan FV (2011) Dephenolization and decolorization of olive mill wastewater through sequential batch and co-culture applications. World J Microbiol Biotechnol 27: $107-114$

Faust BC, Hoigne J (1987) Sensitized photooxidation of phenols by fulvic acid and in natural waters. Env Sci Technol 21:957-964

Gamaralalage D, Sawai O, Nunoura T (2019) Degradation behavior of palm oil mill effluent in Fenton oxidation. J Hazard Mat 364:791799

Golmakani MT, Rezaei K, Mazidi S, Razavi SH (2012) Effect of alternative $\mathrm{C} 2$ carbon sources on the growth, lipid, and $\gamma$-linolenic acid production of Spirulina (Arthrospira platensis). Food Sci Biotechnol 21:355-363

Griffiths MJ, Garcin C, van Hille RP, Harrison STL (2011) Interference by pigment in the estimation of microalgal biomass concentration by optical density. J Microbiol Meth 85:119-123

Hach (2014) Platinum cobalt standard method for color (true and apparent). https://www.hach.com/asset-get.download-en.jsa?id= 7639982533. Accessed on 27 July 2018

Haruna S, Mohamad SE, Jamaluddin H, Yahya A (2018) Phycoremediation of palm oil mill effluent (POME) by freshwater microalgae. Adv Sci Lett 24:3652-3657

Hirooka T, Akiyama Y, Tsuji N, Nakamura T, Nagase H, Hirata K, Miyamoto K (2003) Removal of hazardous phenols by microalgae under photoautotrophic conditions. J Biosci Bioeng 95:200-203

Hurtado L, Amado-Piña D, Roa-Morales G, Peralta-Reyes E, Martin del Campo E, Natividad R (2016) Comparison of AOPs efficiencies on phenolic compounds degradation. J Chem 2016:4108587

Igwe JC, Onyegbado CC (2007) A review of palm oil mill effluent (POME) water treatment. Glob J Env Res 1:54-62

Jacobs LE, Weavers LK, Houtz EF, Chin YP (2012) Photosensitized degradation of caffeine: role of fulvic acids and nitrate. Chemosphere 86:124-129

Klekner V, Kosaric N (1992) Degradation of phenols by algae. Env Technol 13:493-501

Kongnoo A, Suksaroj T, Intharapat P, Promtong T, Suksaroj C (2012) Decolorization and organic removal from palm oil mill effluent by Fenton's process. Env Eng Sci 29:855-859

Kulkarni SJ, Kaware JP (2013) Review on research for removal of phenol from wastewater. Int J Sci Res Publ 3:1-5

Lee HC, Lee M, Den W (2015) Spirulina maxima for phenol removal: study on its tolerance, biodegradability and phenol-carbon assimilability. Water Air Soil Pollut 226:395
Lika K, Papadakis IA (2009) Modeling the biodegradation of phenolic compounds by microalgae. J Sea Res 62:135-146

Lindner AV, Pleissner D (2019) Utilization of phenolic compounds by microalgae. Algal Res 42:101602

Mohammadi S, Kargari A, Sanaeepur H, Abbassian K, Najafi A, Mofarrah E (2015) Phenol removal from industrial wastewaters: a short review. Desal Water Treat 53:2215-2234

Naoki S, Norio M, Yoshiro M, Nobuo U (1979) Effect of growth temperature on lipid and fatty acid compositions in the blue-green algae, Anabaena variabilis and Anacystis nidulans. Biochim Biophys Acta -Lipids Lipid Metab 572:19-28

Norvill ZN, Toledo-Cervantes A, Blanco S, Shilton A, Guieysse B, Muñoz R (2017) Photodegradation and sorption govern tetracycline removal during wastewater treatment in algal ponds. Bioresour Technol 232:35-43

Nur MMA, Buma AG (2019) Opportunities and challenges of microalgal cultivation on wastewater, with special focus on palm oil mill effluent and the production of high value compounds. Waste Biomass Valoriz 10:2079-2097

Nur MA, Garcia GM, Boelen P, Buma AGJ (2019a) Enhancement of Cphycocyanin productivity by Arthrospira platensis when growing on palm oil mill effluent in a two-stage semi-continuous cultivation mode. J Appl Phycol 31:2855-2867

Nur MMA, Muizelaar W, Boelen P, Buma AGJ (2019b) Environmental and nutrient conditions influence fucoxanthin productivity of the marine diatom Phaeodactylum tricornutum grown on palm oil mill effluent. J Appl Phycol 31:111-122

Papazi A, Karamanli M, Kotzabasis K (2019) Comparative biodegradation of all chlorinated phenols by the microalga Scenedesmus obliquus - the biodegradation strategy of microalgae. JBiotech 296:61-68

Poh PE, Yong WJ, Chong MF (2010) Palm oil mill effluent (POME) characteristic in high crop season and the applicability of high-rate anaerobic bioreactors for the treatment of POME. Indust Eng Chem Res 49:11732-11740

Pradeep NV, Anupama S, Navya K, Shalini HN, Idris M, Hampannavar US (2015) Biological removal of phenol from wastewaters: a mini review. Appl Water Sci 5:105-112

Priyadharshini SD, Bakthavatsalam AK (2016) Optimization of phenol degradation by the microalga Chlorella pyrenoidosa using PlackettBurman design and response surface methodology. Bioresour Technol 207:150-156

Safarzadeh-Amiri A, Bolton JR, Cater SR (1996) The use of iron in advanced oxidation processes. J Adv Oxidat Technol 1:18-26

Scragg AH (2006) The effect of phenol on the growth of Chlorella vulgaris and Chlorella VT-1. Enz Microb Technol 39:796-799

Semple KT, Cain RB (1996) Biodegradation of phenols by the alga Ochromonas danica. Appl Environ Microbiol 62:1265-1273

Sroka Z, Cisowski W (2003) Hydrogen peroxide scavenging, antioxidant and anti-radical activity of some phenolic acids. Food Chemical Toxicol 41:753-758

Stephen DP, Ayalur BK (2017) Effect of nutrients on Chlorella pyrenoidosa for treatment of phenolic effluent of coal gasification plant. Env Pollut Res 24:13594-13603

Sukumaran P, Bin Omar H, Nulit RB, Halimoon NB, Simoh SB, Bin Ismail A (2018) The prospects of the cultivation of Arthrospira platensis under outdoor conditions in Malaysia. Jordan J Biol Sci 11:419-426

Surkatti R, Al-Zuhair S (2018) Microalgae cultivation for phenolic compounds removal. Env Sci Pollut Res 25:33936-33956

Vlyssides A, Barampouti EM, Mai S, Sotiria M, Eleni N (2011) Degradation and mineralization of gallic acid using Fenton's reagents. Env Eng Sci 28:515-520

Zainal A, Yaakob Z, Takriff MS, Rajkumar R, Ghani JA (2012) Phycoremediation in anaerobically digested palm oil mill effluent 
using cyanobacterium, Spirulina platensis. JBiobased Mat Bioenergy 6:704-709

Zarrouk, C. (1966). Contribution a l'etude d'une Cyanophycee. Influence de Divers Facteurs Physiques et Chimiques sur la croissance et la photosynthese de Spirulina maxima. Thesis. University of Paris, France
Shavandi MA, Haddadian Z, Ismail MHS, Abdullah N, Abidin ZZ (2012) Removal of Fe(III), Mn(II) and Zn(II) from palm oil mill effluent (POME) by natural zeolite. J Taiwan Inst Chem Eng 43:750-759

Publisher's note Springer Nature remains neutral with regard to jurisdictional claims in published maps and institutional affiliations. 